\title{
Why the gender difference in susceptibility to rheumatoid arthritis?
}

A recent community based study conducted in the Norwich Health Authority ${ }^{1}$ confirmed the previous observations of an increased incidence of rheumatoid arthritis (RA) among women. ${ }^{2} 3$ The figure shows updated incidence values from this study, covering all onsets which occurred in 1990 and 1991 . These recent data indicate that the excess incidence of RA in women is firmly established before the menopause, after which the incidences for both men and women appear to increase uniformly. The exception is in those older than 80, among whom the excess is no longer apparent. The reasons behind the excess incidence in women are therefore likely to be associated with events peculiar to women before the menopause, in particular hormonal and reproductive exposures.

A possible role for exogenous female sex hormones in both the aetiology and treatment of RA has been extensively investigated on numerous occasions over the past four decades. The most important observation came in 1978 from the Royal College of General Practitioners (RCGP) study which provided evidence that oral contraceptives protected against the development of RA. ${ }^{4}$ This relationship has been studied extensively since then, ${ }^{5}$ though there remains no consensus whether oral contraceptives do have a role in reducing susceptibility to RA. ${ }^{6}$ Similarly, studies of the role of postmenopausal oestrogen treatment have also shown conflicting evidence. ${ }^{7-10}$ It is of interest to note that, apart from the original RCGP study, the only studies to report a protective effect for exogenous hormones were of a case-control design, raising the possibility that the findings were attributable to some methodological flaw to which case-control studies are particularly susceptible. Furthermore, the hypothesis that exogenous female hormones reduce susceptibility to RA, while of interest, could not explain the increased incidence of the disease among women.

Endogenous sex hormones have also been strongly implicated in the aetiology of RA, given the reported waxing and waning of symptoms during the different phases of the female menstrual cycle. ${ }^{11}$ Studies of endogenous hormones



Incidence of rheumatoid arthritis in men ( $\square$ ) and women ( $\square$ ) in Norwich Health Authority during 1990-91. have consistently found that men with RA tend to have decreased levels of testosterone-a hormone with immunosuppressive properties. $^{12-15}$ Interestingly, certain HLA alleles appear to act as markers for low testosterone levels. ${ }^{16}$ Among women the findings are less clear, with some studies reporting decreased levels of both testosterone and dehydroepiandrosterone sulphate (DHEAS) in women with RA, ${ }^{17} 18$ and others finding no difference. ${ }^{19-21}$ These studies are difficult to interpret, however, as serum hormone measurements were taken from individuals with established disease and it is impossible to separate out cause and effect. Of interest are recent results from a prospective study comparing baseline DHEAS values in 35 women who subsequently developed RA and in 140 unaffected women. The RA women had significantly decreased concentrations of DHEAS; the difference was most prominent in premenopausal women. ${ }^{22}$ The hypothesis of androgen deficiency as a possible cause of RA is therefore of much interest and, given that male and female androgen concentrations are most disparate before the female menopause, it could also help explain the gender difference in incidence. ${ }^{23}$

The effects of pregnancy are also, at first sight, rather paradoxical and unlikely to explain the increased incidence in women. Pregnancy is apparently protective, as women with RA tend to be more likely to be nulliparous than comparable controls and the nine month period of pregnancy appears to provide a time of remission for most women with established disease. ${ }^{24}$ These two observations may not be directly related, as the apparent protective effect of parity appears more likely to be the result of an increased risk of disease associated with reduced fecundity. ${ }^{25}$ Further, the postpartum period has been found to be a time of high risk for developing first symptoms of $\mathrm{RA},{ }^{26-28}$ with the increased risk postpartum being greatest after the first pregnancy. ${ }^{26}$ This increase in postpartum risk after the first pregnancy is likely to be explained by breast feeding: one study found that women who breast fed after their first pregnancy were up to five times more likely to develop RA within 12 months than women who did not breast feed. ${ }^{29}$ This risk was even greater for erosive, rheumatoid factor positive disease. These results have been corroborated by a recent study which showed that women with severe RA were likely to have breast fed for longer and breast fed more children than women whose RA was not classified as severe. ${ }^{30}$

A possible biological basis for these observations is an interaction between high levels of prolactin and the immune system. Evidence from animal models indicates that prolactin has a strong proinflammatory nature; hypophysectomised mice did not develop adjuvant arthritis unless they were treated with the hormone. ${ }^{31}$ Other more circumstantial evidence includes the presence of prolactin receptors on $\mathrm{T}$ and $\mathrm{B}$ lymphocytes ${ }^{32}$ and the possible association between the diurnal rhythm of prolactin levels and disease activity in RA. ${ }^{33}$ Indeed, a role for prolactin in the aetiology of RA could help explain, not only the gender difference in the incidence of the disease, but also why infertility and reduced fecundity are associated with $\mathrm{RA}$, given their relationship to hyperprolactinaemia. 
In summary, the premenopausal excess incidence of RA in women is substantial and offers a tantalising path for the investigation of hormonal effects on RA susceptibility and activity. Androgen deficiency and prolactin excess might, at least in part, explain the excess incidence in women, and also contribute to understanding the aetiology of the disease.

ARC Epidemiology Research Unit,

University of Manchester Medical School,

Oxford Road, Manchester M13 9PT,

United Kingdom

1 Symmons D P M, Barrett E M, Bankhead C R, Scott D G I, Silman A J. The incidence of rheumatoid arthritis in the United Kingdom: results from the Norfolk Arthritis Register. Br ₹ Rheumatol 1994; 33: 735-9.

2 Linos A, Worthington J W, O'Fallon M, et al. The epidemiology of rheumatoid arthritis in Rochester, Minnesota: a study of incidence, prevalence, and mortality. Am F Epidemiol 1980; 111: 87-98.

3 Gran J T, Magnus J, Mikkelsen K, et al. The incidence of classical and definite theumatoid arthritis in Lillehammer, Norway. Scand $\mathcal{f}$ Rheum 1986; 15 (suppl 9): 7 .

4 Wingrave S J, Kay C R. Reduction in incidence of rheumatoid arthritis associated with oral contraceptives. Lancet 1978; i: 569-71.

5 Spector T D, Hochberg M C. The protective effect of the oral contraceptive pill on rheumatoid arthritis. F Clin Epidemiol 1990; 43: 1221-30.

6 Hazes J M W, Van Zeben D. Oral contraception and its possible protection against rheumatoid arthritis. Ann Rheum Dis 1991; 50: 72-4.

7 Vandenbroucke J P, Witteman J C M, Valkenburg H A, et al. Noncontraceptive hormones and rheumatoid arthritis in perimenopausal and postmenopausal women. $7 A M A$ 1986; 255: 1299-303.

8 Koepsell T D, Dugowson C E, Nelsen J L, Voigt L F, Daling J R. Noncontraceptive hormones and the risk of rheumatoid arthritis in menocontraceptive hormones and the risk of rheumat.

9 Spector T D, Brennan P, Harris P, Studd J W W, Silman A J. Does estrogen replacement therapy protect against rheumatoid arthritis? $f$ Rheumatol 1991; 18: 1473-6.

10 Carette S, Marcoux S, Gingras S. Postmenopausal hormones and the incidence of rheumatoid arthritis. $\mathcal{F}$ Rheumatol 1989; 16: 911-3.

11 Latman N S. Relation of menstrual cycle to symptoms of rheumatoid arthritis. $A m$ f Med 1983; 74: 957-60.

12 Gordon D, Beastall G H, Thomson J A, Sturrock R D. Androgenic status and sexual function in males with rheumatoid arthritis and ankylosing spondylitis. $Q \mathcal{F}$ Med 1986; 231: 671-9.

13 Cutolo M, Balleari E, Accardo S, et al. Preliminary results of serum androgen level testing in men with rheumatoid arthritis. $f$ Chron Dis 1984; 5: $636-43$.
14 Spector T D, Ollier W, Perry L A, Silman A J, Thompson P W, Edwards A. Free and serum testosterone levels in 276 males: A Edwards A. Free and serum testosterone levels in 276 males: A comparative study of rheumatoid arthritis, ank

15 Spector T D, Perry L A, Tubb G, et al. Low testosterone levels in males with rheumatoid arthritis. Ann Rheum Dis 1988; 47: 65-8.

16 Ollier W, Spector T, Silman A, et al. Are certain HLA haplotypes responsible for low testosterone in males? Dis Markers 1989; 7: 139-43.

17 Sambrook P N, Eisman J A, Champion G D, Pocock N A. Sex hormone status and osteoporosis in postmenopausal women with rheumatoid arthritis. Arthritis Rheum 1988; 31: 973-8.

18 Feher K G, Feher T, Merety K. Interrelationship between the immunological and steroid hormone parameters in rheumatoid arthritis. Exp Clin Endocrinol 1986; 87: 38-42.

19 Spector T D, Perry L A, Tubb G, Huskisson E C. Androgen status of females with RA. Br fRheumatol 1987; 26: 316-7.

20 Cutolo M, Balleari E, Giusti M, Monachesi M, Accardo S. Sex hormone status in women suffering from rheumatoid arthritis. $\mathcal{F}$ Rheumatol 1986; 13: 1019-23

21 Dougados M, Nahoul K, Benhamou L, Amor B. Androgen plasma levels in female rheumatoid arthritis patients. Arthritis Rheum 1983; 26: 935-6.

22 Masi A T, Chatterton R T, Comstock G W, Malamet R L, Kochberg M C. Decreased serum dehydroepiandrosterone sulphate (DHAS) levels before onset of RA in younger, premenopausal women: a controlled, prospective study. Arthritis Rheum 1994; 37 (suppl): S315.

23 Cutolo M, Accardo S. Sex hormones, HLA and rheumatoid arthritis. Clin Exp Rheumatol 1991; 9: 641-6.

24 Da Silva J A P, Spector T D. The role of pregnancy in the course and aetiology of rheumatoid arthritis. Clin Rheumatol 1992; 11: 189-94.

25 Nelson J L, Koepsell T D, Dugowson C E, Voigt L F, Daling J R, Hansen J A. Fecundity before disease onset in women with rheumatoid arthritis. Arthritis Rheum 1993;36: 7-14.

26 Silman A J, Kay A, Brennan P. Timing of pregnancy in relation to the onset of rheumatoid arthritis. Arthritis Rheum 1992; 35: 152-5.

27 Lansink M, de Boer B A C, Dijkmans B A C, Vandenbroucke J P, Hazes J M W. The onset of rheumatoid arthritis in relation to pregnancy and childbirth. Clin Exp Rheumatol 1993; 11: 171-4.

28 Del Junco D J, Annegers J F, Coulam C B, Luthra H S. The relationship between rheumatoid arthritis and reproductive function. $\mathrm{Br} F$ Rheumatol 1989; 28 (suppl 1): 33 .

29 Brennan P, Silman A. Breast-feeding and the onset of rheumatoid arthritis. Arthritis Rheum 1994; 37: 808-13.

30 Jorgensen C, Picot M C, Bologna C, Lamarque J L, Sany J. Breast feeding influences the prognosis of rheumatoid arthritis (RA). Arthritis Rheum 1994; 37 (suppl): S314

31 Nagy E, Berczi I, Wren G, Asa S L, Kovacs K. Immunomodulation by bromocriptine. Immunopharmacology 1983; 6: 231-43.

32 Gagnerault M C, Touraine P, Savino W, Kelly P A. Dardenne M Expression of prolactin receptors in murine lymphoid cells in normal and autoimmune situations. F Immunol 1993; 150: 5673-81.

33 Chikanza I C, Pownall R, Panayi G S. Immunoendocrine interactions in the pathogenesis of rheumatoid arthritis: initiating and perpetuating factors? Br fRheumatol 1990; 29 (suppl 2): 22 . 